\section{LAS EDADES DE LA CREATIVIDAD. ALGUNAS CONSIDERACIONES SOCIOLÓGICAS SOBRE LA ORIGINALIDAD CREATIVA EN LA MODERNIDAD}

\author{
Juan A. Roche Cárcel \\ Universidad de Alicante \\ ORCID iD: https://orcid.org/0000-0003-1522-5918
}

Ja.Roche@ua.es

Cómo citar este artículo/Citation: Roche Cárcel, J. A. (2020). Las edades de la creatividad. Algunas consideraciones sociológicas sobre la originalidad creativa en la modernidad. Arbor, 196 (797): a569. https://doi.org/10.3989/arbor.2020.797n3006

Recibido: 20 enero 2020. Aceptado: 29 marzo 2020.

RESUMEN: Tras reseñar diferentes sociólogos que han destacado la importancia de la originalidad para la creatividad, este artículo tiene como objetivo analizar el conflicto entre generaciones y la alternancia continuidad-cambio social que genera y que constituye el motor de la creatividad. Para ello, se indaga en la etimología del concepto de 'originalidad', con el fin de encontrar los términos básicos con los que se asocia. Como se verá, concretamente lo hace con las palabras origen y originario $\mathrm{u}$ originante, que se fusionan en el proceso creador, de manera que este establece una narrativa temporal en la que el pasado, el presente y el futuro quedan interrelacionados. Esta narrativa temporal se concreta en la sociedad y en la cultura modernas -especialmente, en el arte, la ciencia, la democracia y el capitalismo, cuatro de las creaciones más destacadas de la etapa-, diferenciándose la primera modernidad por su evolución desde la creatividad infantil o juvenil hacia la senil, y la segunda por la decadencia. Finalmente, el artículo concluye que la creatividad se define por la originalidad, porque construye una narración histórica y porque puede ayudar a eliminar la confusión del presente; que la infancia y la juventud de los creadores se vincula con el conflicto generacional; y que la primera modernidad constituye una etapa infantil o juvenil, mientras que la segunda se define por el declive generalizado físico, cultural y social.

PALABRAS CLAVE: Sociología de la creatividad; conflicto de generaciones; modernidad; envejecimiento social.

\section{THE AGES OF CREATIVITY. SOME SOCIOLOGICAL CONSIDERATIONS ABOUT CREATIVE ORIGINALITY IN MODERNITY}

Copyright: (C) 2020 CSIC. Este es un artículo de acceso abierto distribuido bajo los términos de la licencia de uso y distribución Creative Commons Reconocimiento 4.0 Internacional (CC BY 4.0).

ABSTRACT: After reviewing different sociologists who have highlighted the importance of originality for creativity, this article will analyse the conflict between generations and the social continuity-change alternation that generates and constitutes the engine of creativity. To do this, the etymology of the concept of 'originality' is investigated in order to find the basic terms with which it is associated. As will be seen, specifically, it does so with the words origin and originary, which merge in the creative process, establishing a temporary narrative in which the past, present and future are interrelated. This temporary narrative takes shape in modern society and culture - especially in art, science, democracy and capitalism, four of the most prominent creations of the period - with the first modernity distinguished by its evolution from childhood or youthful creativity towards decrepitude, and the second by decline. Finally, the article concludes that creativity is defined by originality because it builds a historical narrative, and because it can help eliminate the confusion of the present; that the childhood and youth of the creators are linked to generational conflict; and that the first modernity constitutes a childish or youthful period, while the second is defined by generalised physical, cultural and social decline.

KEYWORDS: Sociology of creativity; generational conflict; modernity; social aging. 


\section{INTRODUCCIÓN: LA BÚSQUEDA DE ORIGINALIDAD, UNA DE LAS CARACTERÍSTICAS MÁS IMPORTANTES DE LA CREATIVIDAD}

\subsection{La persecución de la originalidad en la creatividad, según la Sociología; hipótesis de partida y objetivos}

Es frecuente hallar en la literatura sociológica que investiga la creatividad que esta busca la novedad, la innovación, la originalidad. Por ejemplo, para E. Durkheim (1987, p. 14), toda moral tradicional debe ser alterada para que no se atrofie y precisamente esta innovación va de la mano del proceso de creación. Según H. Joas, la creatividad examina nuevos caminos alejados de la rutina, del capricho y de lo cotidiano, de modo que esta liberación posibilita la creación y la construcción de nuevas acciones (Joas, 2013, p. 189 y p. 254). Sánchez Capdequí (2018, p. 6), por su parte, considera que la experiencia creativa contemporánea persigue de una manera casi obsesiva la novedad y la originalidad, se dirige a la construcción del individuo mismo, y por eso es entendida como ruptura, diferencia y divergencia. También para R. Collins la originalidad y la innovación son consustanciales a la creatividad, aunque representan realidades minoritarias $y$, para que fructifiquen, deben producirse en condiciones muy determinadas (RubioArostegui, Pecourt y Rius Ulldemolins, 2016, p. 131). Finalmente, el padre de la sociobiología, E. O. Wilson (2018, p. 11), defiende que la creatividad supone la exploración innata de la originalidad.

Sin embargo, no es habitual que los sociólogos precisemos qué significa la palabra originalidad y entremos más en profundidad en cómo se interrelaciona con el tiempo. Es lo que voy a hacer en este artículo, con los siguientes objetivos:

1) Buscar diferentes sociólogos que destaquen la importancia de la originalidad para la creatividad.

2) Indagar en la etimología de este último concepto, con el fin de encontrar los términos básicos con los que se asocia.

3) Comprobar si el proceso creador remite al origen y a lo originario $u$ originante, al pasado y al futuro y, si es así,

4) desvelar el tipo de narrativa temporal que construye la creatividad en la modernidad.

5) Analizar el dinamismo histórico propiciado por el conflicto entre generaciones -entre la de los niños o jóvenes y la de los viejos- y estudiar la alternancia continuidad y cambio social como motor de la creatividad.
6) Concretar todo esto en la sociedad y en la cultura moderna -especialmente en el arte, la ciencia, la democracia y el capitalismo, cuatro de las creaciones más destacadas de la etapa-, para confirmar si la primera modernidad se adscribe a una creatividad infantil y juvenil, y si la segunda lo hace a una más envejecida.

Para conseguir estos objetivos, he estructurado el artículo en los cinco siguientes apartados, subdivididos en otros tantos: 1 . Introducción: la búsqueda de originalidad, una de las características más importantes de la creatividad; 2 . La infancia y la juventud y el conflicto entre generaciones impulsor de la creatividad; 3 . El rejuvenecimiento de las ciencias y las artes de la primera moderrnidad; 4. La pérdida de protagonismo de la juventud y el envejecimiento de la sociedad y de la creatividad en la segunda modernidad; y 5. Conclusiones.

\subsection{La etimología del concepto de originalidad: la li-} gazón entre el origen y lo originario u originante

Originalidad se define como la "cualidad de original", "la acción o actitud originales" (María Moliner, 2007, s.v. originalidad) y el "hecho o rasgo original" (Seco, 1999, s.v. originalidad). Originalidad remite a "original", que es "de origen", a "la primera de varias cosas que proceden sucesivamente una de otra" (María Moliner, 2007, s.v. originalidad), a la "cosa primera o primitiva, anterior a toda elaboración, cambio o sustitución" (Seco, 1999, s.v. originalidad). Sin embargo, originalidad también tiene otro significado que contradice el anterior, lo "que no imita a otros" (Seco, 1999, s.v. originalidad), lo "distinto a lo acostumbrado o contrario a lo acostumbrado", algo "característico", "especial", "extraordinario", "extravagante", "nuevo" y lo que está asociado a términos como descubrir, explorar, innovar, inventar... (María Moliner, 2007, s.v. originalidad).

Así pues, la originalidad -lo original- remite a los conceptos de 'origen' y de 'originario', es decir, tanto a 'lo primero' o 'primitivo' como a 'lo producido de forma novedosa'. Por consiguiente, el origen y lo originado u originante van juntos, ya que lo primero constituye el fundamento de lo segundo, mientras que lo originario constituye el origen de algo y lo emanado de manera innovadora, y también el momento anterior a toda transformación. Pero la intrincada interrelación existente entre estos términos no acaba aquí, pues lo originado tiene, a su vez, que convertirse en origen de algo, en una nueva semilla que germine una nueva planta. 
En suma, ambos conceptos se fusionan, de manera que el origen es inseparable de lo originario y esto último de lo primero, lo que explica que en la creación literaria, artística, o de cualquier otro campo -añadiría yo- la pretendida originalidad signifique realmente una vuelta a los orígenes, sin olvidar que, tras su forma más original, esta anuncia lo que ha de venir (Steiner, 2002, p. 94 y p. 164).

\section{LA INFANCIA Y LA JUVENTUD Y EL CONFLICTO ENTRE GENERACIONES IMPULSOR DE LA CREATIVIDAD}

\subsection{La infancia creadora; la creación constituye un retorno a la infancia}

El origen de la creatividad se asienta en la época de la infancia, tal y como ha demostrado el Psicoanálisis. Al respecto, en líneas generales pueden señalarse dos corrientes sobre el papel de la infancia en la creatividad. Un ejemplo representativo de la primera perspectiva la ofrece D. W. Winnicott (2013, pp. 42-46, p. 125 y p. 163), quien piensa que la etapa en la que el bebé se ubica en esa zona intermediaria de experiencia, porque siente que está al mismo tiempo fusionado y separado de su madre y porque pertenece al unísono a su interior y a lo exterior -la realidad-, es clave para su maduración, la construcción de su personalidad y la creatividad. Precisamente es esta la que establece un juego recíproco entre la originalidad y la aceptación de la tradición, base de la incitante inventiva del niño, un producto de la tensión entre la separación y la unión con su madre. De hecho, una buena relación con ella será decisiva para la salud psíquica del niño y para que fluya adecuadamente su creatividad primaria. Además, ello le permitirá, cuando es adulto y durante toda su vida, tener intensas experiencias relacionadas con las artes, la religión, la vida imaginativa y la labor científica creadora.

Desde Freud, es más común en el Psicoanálisis que la creatividad brote de un trauma infantil, de una "herida", "enfermedad" o "patología". Así, el espacio y el tiempo transicional en el que se desarrolla la creatividad en el infante está vinculado con lo que los psicólogos denominan "la ausencia de la madre" -"el complejo de la madre muerta", según André Green (1993, pp. 209 y ss.)- y su capacidad para sustituir esa ausencia mediante la imaginación. Y es que los niños que sufren de este abandono precoz sienten dolor y melancolía, una nostalgia de su fusión feliz con el cuerpo materno, y reparan sus emociones a través del aumento de la capacidad de simbolización, que les otorga un sentido al sinsentido de su falta. No extrañe que la creación suponga -de la misma manera que el éxtasis religioso- un retorno al estado casi paradisíaco en el que el niño se disponía en el feto materno. Por tanto -de acuerdo a esta posición del Psicoanálisis-, la creatividad constituye una energía psíquica pretérita que deviene un proceso reparatorio, más o menos logrado, al sufrimiento o trauma infantil experimentado por el abandono de la madre. Ese proceso de compensación se lleva a cabo mediante dos mecanismos defensivos básicos, la disociación y la sublimación, y acompañará siempre a todo proceso de creación, ya se trate de los mitos, de las religiones o de cualquier otra actividad creadora (López Mondéjar, 2015, pp. 28-77).

En suma, en relación con la creatividad del Psicoanálisis pueden extraerse algunas inferencias interesantes para la Sociología:

1. a) Una buena crianza materna o una carencia de ella se encuentran en la base del niño creador, y en el futuro del adulto. No en balde, aunque la creatividad representa un universal, una actividad común de hombres y mujeres (Winnicott, 2013, pp. 42-46 y p. 125), la psicología de lo creativo es en realidad femenina, en la medida en que las obras de creación brotan de las profundidades inconscientes y, más específicamente, del "reino de las madres" (Jung, 2014, p. 95), del que se nutren la realidad objetiva y la misma actividad espiritual personal (Eco, 1972, p. 117).

En este sentido, la creatividad supone una vuelta a la infancia, y consecuentemente una reflexión intelectual y emocional de la familia en la que esta se ha incardinado. Esto quiere decir que la creación es un asunto del creador, pero que está condicionado sociológicamente por la forma institucional y cultural que adopte la familia, y más específicamente dentro de ella la maternidad.

2. a) En la primera posición del Psicoanálisis, la creatividad se vincula con la crianza y el desarrollo de la personalidad o, lo que es lo mismo, con el "vivir creador", con la "condición de estar vivo" (Winnicott, 2013, p. 119). Ello significa que la creatividad es una actividad humana consustancial al vivir y a la construcción del sujeto a lo largo de su socialización, que es al tiempo individual y social, interiorizante y exteriorizante.

3. - ) Desde la segunda visión, ciertamente, la creatividad puede ser impulsada por la falta o la enfermedad, de hecho, numerosos creadores (artistas, pintores, músicos, escritores, poetas...) encajan perfecta- 
mente en esta definición (López Mondéjar, 2015, p. $55 \mathrm{ss})$, al estar determinadas sus biografías por una infancia que no fue todo lo afortunada que debería haber sido. Siendo esto cierto, creo que el hueco o vacío femenino que una vez habitamos -feliz o desgraciadamente- y al que desean retornar con su actividad los creadores, expresa que estos están impelidos a rellenar ese abismo profundo con la construcción imaginaria de la creatividad, pero también con la necesidad psíquica de recogerse, esconderse y protegerse. De este modo la creatividad se convierte en una metáfora de una humanidad quebradiza e incierta, obligada a acurrucarse ante la intemperie de la existencia y de las insuficiencias e imperfecciones connaturales de la propia sociedad, así como de la fragilidad que este no acabamiento conlleva en sus miembros. Por tanto, la vinculación de la creatividad con la infancia señala, en último extremo, la indigencia de toda sociedad creada y de todo creador adulto.

4. a) Ello supone asimismo que uno de los rasgos caracterizadores de los creadores lo constituya su infantilidad (Gardner, 2010, pp. 51 y ss.), curiosidad, espontaneidad, frescura y pureza. Así, los productos del artista son la consecuencia de su fijación en una fase infantil no superada (Neumann, 2004, p. 36) y siempre recreada y revivida.

Como se verá a continuación, ello conlleva un choque generacional del creador consigo mismo y con su sociedad.

\subsection{La juventud creadora y el conflicto entre generaciones}

Al igual que sucede en la infancia, las primeras impresiones y vivencias de la juventud orientan cualquiera de sus experiencias más tardías. Sin embargo, también niegan las adquiridas (Mannheim, 1993, p. 196 y p. 216) y de ahí que, frente a la vejez a la que se le adjudica un carácter conservador, esta etapa de la vida es la que posee uno más tempestuoso e innovador. No en balde, es consustancial al adolescente su inmadurez y que intente "asesinar" lo heredado de su sociedad y ello para alcanzar la categoría de adulto (Winnicott, 2013, pp. 215 y ss.). Por eso, los jóvenes no son responsables del mundo recibido, sino que componen "la fotografía de los tiempos que cambian" (Bauman y Leoncini, 2018, p. 17). Y es que poseen los rasgos más estimulantes del pensamiento creador, los sentimientos novedosos y frescos, las ideas para una nueva vida; de hecho, la sociedad requiere, para su revitalización y rejuvenecimiento, ser convulsionada por sus aspiraciones. Pero, por otra parte, ella reclama a los jóvenes, para que puedan integrarse, que esta inmadurez congénita obtenga una cura, lo que únicamente es posible con el paso del tiempo, con la madurez que este pueda aportar (Winnicott, 2013, pp. 215-227), obtenida mediante el choque, y las respuestas que conlleva, entre la forma juvenil de ver el mundo y la de la propia sociedad.

Ello supone que las vivencias reunidas por los jóvenes en el curso de su existencia se acumulen por adición y que se articulen dialécticamente y en muchas ocasiones en combate. Concretamente, esa lucha tiene lugar a partir de esos sedimentos acumulados que, al hacerse conscientes, son memorizados o transformados, si bien estos últimos lo son únicamente superficialmente, pues los más profundos permanecen (Mannheim, 1993, pp. 216-219). Ello es así porque los individuos, en su proceso de socialización, necesitan apoyarse en el saber previo existente y prolongarlo, de modo que este conocimiento deviene el fruto del desarrollo de la humanidad, esto es, de su largo proceso de aprendizaje. Al respecto, conviene tener presente que el sujeto principal de este saber no es el individuo, sino los grupos humanos y más específicamente la cadena de generaciones (Elias, 2013, p. 15 y p. 53).

Veamos entonces qué significa el concepto generaciones, qué papel asumen los jóvenes en ellas, cómo funcionan y cómo se vinculan con la creatividad (Halbwachs, 2011, p. 112; Mannheim, 1993, pp. 196-232; Martin, 2008, pp. 98 y ss.; Ortega y Gasset, 1983, p. 149; Ortega y Gasset, 2008, pp. 43-149).

La generación es el conjunto de seres humanos que tienen la misma edad y supone un compromiso dinámico entre la masa y el individuo. Además, representa, junto con los valores naturales -pues se fundamenta, en último extremo, en el ritmo biológico del nacimiento y la muerte-, el concepto fundamental del acontecer histórico social, la clave que permite conocer sus movimientos, cambios y resistencias. Así, lo importante no es que las generaciones se sucedan, sino que conviven y son contemporáneas y, por tanto, no coetáneas, lo que quiere decir que se "solapan o empalman" y que entran en "polémica". Se explica, pues, que el conflicto y la colisión constituyan el fundamento de la materia histórica de cualquier convivencia social y del dinamismo dramático de las sociedades. Pero en la base de ello está el carácter continuo del cambio generacional y el hecho de que el ser humano sea un eterno inadaptado que constantemente quiere modificar lo que ha heredado para ajustarlo a su propia sensibilidad y para imprimirle su singular huella. Así, cada generación trabaja en dos 
dimensiones simultáneas: recibir de la anterior lo vivido, esto es, las ideas, los valores, las instituciones, etc., y dejar que brote y se desarrolle su propia espontaneidad y cosmovisión. En este sentido, existen dos tipos diferentes de generaciones: las que conviven con la de los mayores y las que la combaten. Es cierto que en las primeras los jóvenes se solidarizan con los viejos y se supeditan a ellos, tanto en la política como en la ciencia o en las artes, dominadas por la experiencia de las personas adultas; de ahí que estos tiempos estén envejecidos -cuestión que sucede en la segunda modernidad, como voy a tratar más adelante-. Por el contrario, -en la primera modernidad- las edades que están dominadas por la juventud son iniciáticas, de beligerancia constructiva o destructiva y por tanto de creatividad.

\section{EL REJUVENECIMIENTO DE LAS CIENCIAS Y DE LAS ARTES DE LA PRIMERA MODERNIDAD}

\subsection{El rejuvenecimiento de la ciencia}

Este conflicto entre generaciones se visualiza, de un modo explícito, en la modernidad, la etapa que básicamente va desde 1890 hasta 1930 (Bell, 1992, p. 117) -la primera modernidad-, si bien se extiende hasta 1973, cuando se inicia la segunda modernidad. Pues bien, es en la primera en la que los lazos entre la cultura y la juventud y entre esta y la propia modernidad se hacen más evidentes (Hobsbawm, 2013, pp. 112-113), mientras que -como se verá- la segunda envejece.

Cierto, la primera modernidad es joven, pues anuncia con entusiasmo fronteras que se abren inesperadamente, nuevas historias para contar y novedosos finales imaginados. De hecho, la novedad y la originalidad se convierten en los rasgos característicos hasta la Primera Guerra Mundial (Watson, 2002, p. 19), más concretamente, de 1905 a 1908 -la década cubista, la belle époque, los años del banquete-, tiempos en los que se produce un renovado vigor cultural que nada tiene que ver con la decadente, negacionista y negativa actitud hacia el mundo (visto como distante) de finales del siglo XIX (Barzun, 2001, p. 949 y p. 1005). En concreto, esta etapa genera cuatro formas de energía: la práctica y la que venera la violencia, los grandes logros artísticos, las innovaciones científicas y las reformas sociales -por ejemplo, las actuales concepciones del Estado y de la democracia representativa- ${ }^{1}$. En este apartado me dedicaré a la ciencia y al arte, y más adelante, a la guerra, la democracia representativa y la economía.
Con respecto a la ciencia, pueden resumirse dos acontecimientos innovadores, los dos pilares fundamentales de la física moderna -la teoría especial y general de la relatividad y la teoría cuántica-, estimados los dos logros más sobresalientes de los últimos cien años (Chown, 2007, prefacio y pp. 19-141; Greene, 2006, pp. 15-180 y pp. 333-335; Sánchez Ron, 2000, pp. 49-117). La primera teoría de impacto la desarroIla Einstein en dos fases, siendo la inicial la conocida como la teoría especial de la relatividad, de 1905, una revolucionaria propuesta sobre la imagen del espacio y del tiempo que, a partir de ahora, dejan de ser absolutos para transformarse en relativos. $Y$ es que, si el primero se contrae, el segundo se dilata y deviene elástico, lo que quiere decir que los observadores que se hallan en un movimiento relativo con respecto a otros obtendrán unas percepciones diferentes, y todas verdaderas, de la distancia y del tiempo. Así, para una persona que pase a alta velocidad por nuestro lado, el tiempo se ralentiza, esto es, transcurre más lentamente para ella, y el espacio se encoje, sin olvidar que una porción de ese espacio nos parece tiempo, una parte de este. Por tanto, las dos dimensiones que antes parecían estar separadas y ser absolutas ahora se convierten en intercambiables -conforman las dos caras de una misma moneda- y relativas.

Ahora bien, el universo que contemplamos mediante un telescopio, aunque se extiende por el espaciotiempo, en realidad es luz, ya que lo que se mantiene constante en él no son ambas dimensiones, sino la invariable velocidad de la luz. Es, pues, esta la que ha reemplazado la visión tradicional del espacio y del tiempo como estructuras rígidas y objetivas por otra nueva condicionada por el movimiento relativo existente entre el observador y lo observado. Además, la luz no envejece, y en la velocidad de la luz no existe el paso del tiempo, lo que significa que ella constituye el cimiento, la roca sobre la que está construido el universo, y consiguientemente el tiempo y el espacio asumen el papel de arenas movedizas.

En 1915, Einstein crea la teoría general de la relatividad, una novedosa concepción gravitacional que reemplaza a la clásica gravitación universal de Newton. Revela que el espacio deja de ser inmutable y ajeno a su contenido energético-material para transmutarse en un espacio-tiempo curvo de cuatro dimensiones. Concretamente, Einstein precisa que las masas -las estrellas como el sol-, por su peso "alabean", curvan, el espacio-tiempo existente a su alrededor, mientras que otras masas -como los planetas, la tierra- se deslizan libremente por el espacio-tiempo impulsados por 
su propia inercia. Por lo demás esta teoría, difícil de aplicar a las situaciones reales o a la vida cotidiana, es circular, puesto que la materia le indica al espaciotiempo cómo debe curvarse, más tarde el espaciotiempo alabeado instiga a la materia a moverse, y finalmente esta última, que se acaba de desplazar, le comunica al espacio-tiempo cómo debe variar de curvatura. Pero, en cualquier caso, el tamaño total del universo espacial ya no permanece invariable como se pensaba hasta ahora, sino que cambia con el tiempo, esto es, que su estructura se amplía o se reduce.

La segunda de las innovaciones científicas, y la que más ha cambiado el rumbo de la ciencia y de la propia sociedad, al estar omnipresente en la cotidianeidad, ha sido la física cuántica. Esta surge de la lucha por reconciliar la luz y la materia y de ahí que esté esencialmente en desacuerdo con toda la ciencia anterior. Por ejemplo, Niels Bohr, el científico de Copenhague, divide en 1920 el universo en dos dominios regidos por diferentes leyes: por un lado, se encuentra lo muy pequeño -el universo atómico-, gobernado por la mecánica cuántica y, por otro lado, lo muy grande -el mundo cotidiano-, tutelado por las leyes normales o clásicas. Por su parte, el principio de incertidumbre de Heisenberg ha desvelado, en 1927, que la energía y el momento son inciertos, es decir, que ya "no podemos conocer, por cuestiones de principio, el presente en todos sus detalles". Además, al aplicar el principio de incertidumbre a la mecánica cuántica, se descubre que, a escala microscópica, el universo es un ámbito "hormigueante", "frenético" y "caótico". Por consiguiente, desde entonces la Física tiene que ocuparse de la descripción formal de las relaciones entre las percepciones, de manera que el mundo físico pierde algo de su solidez y se difumina -se desvanece- en las bases de su estructura.

Las derivaciones de la teoría general de la relatividad y de la física cuántica posibilitan, asimismo, que en 1928 Hubble demostrara que el universo se halla en expansión, lo que quiere decir que, en el pasado (13,7 mil millones de años atrás) hubo un momento en el que toda la materia estaría concentrada en una pequeña extensión, el big-bang (según lo denominaría después el astrofísico Fred Hoyle), una explosión cósmica que lanza al exterior los contenidos materiales del universo (teoría hoy considerada algo equivocada porque en ese momento no debía haber espacio alrededor del big-bang), los "detritos" de ese estallido, en forma de muchos miles de millones de galaxias, que continúan circulando hacia fuera y expandiendo el universo. Posiblemente, el final de este viaje sería un big-crunch cósmico -un gran crujido-, una gran implosión, un universo apiñado en una masa cósmica comprimida.

El nacimiento del universo narrado por la física cuántica y los astrofísicos entra en conflicto con la noción de los agujeros negros y la teoría de la relatividad propuesta por Einstein, en tanto que la teoría general de la relatividad abarca lo muy grande, mientras que el universo es más pequeño que un átomo. Concretamente, es en las escalas minúsculas donde se produce la incompatibilidad fundamental, ya que la visión de una geometría espacial lisa -el principio fundamental de la relatividad general- queda destruida por las violentas fluctuaciones del mundo cuántico a escalas de distancias mínimas. Ello quiere decir, en esencia, que la relatividad general y la mecánica cuántica "no pueden ser ambas ciertas a la vez", que la ciencia se debate entre una concepción y la otra, y en definitiva que necesita encontrar una armonía entre ambas, una teoría cuántica de la gravedad. Al parecer, la teoría de las supercuerdas ha resuelto la tensión existente entre ambas visiones, demostrando que se requieren la una y la otra y que el matrimonio entre las leyes de lo grande y de lo pequeño es inevitable y necesario (Greene, 2006, pp. 15-17 y p. 192).

\subsection{El carácter infantil y juvenil del arte}

Charles Baudelaire, en El pintor de la vida moderna (2004, pp. 82-91), define el carácter bárbaro o infantil del artista moderno, al escribir que la raíz de su genio está en su curiosidad y en su estado "convaleciente", indicativo de su retorno a la infancia. Y es que el convaleciente -igual que el niño- disfruta de un interés vital por todas las cosas, absorbe con alegría la forma y el color y, debido a su profunda curiosidad, contempla el mundo como algo novedoso y como alguien que está siempre "embriagado". Así pues, el artista moderno es un hombre-niño, mientras que el genio encarna la infancia recobrada, aunque dotada de un espíritu analítico con el que ordena, clasifica y armoniza los materiales acumulados en la memoria de un modo involuntario. En efecto, todos estos materiales son sometidos a una obligada idealización, resultado de una percepción infantil, aguda, potentemente ingenua y consecuentemente mágica.

Pero si el arte moderno se asocia con la infancia, también lo hace con la juventud, y en este sentido son muy significativos las teorías, las prácticas y los cambios producidos, particularmente por las vanguardias artísticas. No en balde ellas inician una nueva etapa artística, impulsada por dos crisis mundiales y por una 
angustia colectiva sin precedentes en la Historia. Por eso, defienden la renovación, el rejuvenecimiento y la novedad, definida por la oposición a lo viejo y lo pretérito (Subirats, 1989, pp. 84 y ss.).

Al respecto, en líneas generales pueden establecerse tres caminos de rebelión juvenil. Uno, el cubismo, supone la culminación de una nueva mirada al arte y al mundo, originada en el impresionismo, pasando por Cézanne, y que se dirige hacia la abstracción. Otro, lleva al surrealismo, al letrismo, al situacionismo, y más tarde a las revueltas estudiantiles y a algunas explosiones terroristas, mientras que el último, tras $\mathrm{M}$. Duchamp, desemboca en la música contemporánea, el neo-dadaísmo, el arte pop y las diferentes prácticas artísticas de la segunda mitad del siglo XX en Estados Unidos (Granés, 2011, p. 46; Watson, 2002, p. 77).

El antecedente de las vanguardias artísticas lo representa el cubismo, de 1907-1908, una corriente que constituye el eje básico del arte del siglo XX. Si las grandes obras de Cézanne -a su vez el precedente inmediato del cubismo- se crearon en los mismos meses en los que Einstein preparaba sus teorías, todo el cambio que estaba experimentando el arte desde el cubismo constituía un reflejo del científico. No en balde, la historia de las vanguardias -como la de la física relativista y la mecánica cuántica- puede concebirse como un procedimiento de purificación y de búsqueda de lo esencial (Danto, 1999, p. 87), lo que explica que tengan en común la exploración de las unidades fundamentales, de esa realidad más profunda de la que podrían surgir las nuevas formas (Watson, 2002, pp. 77-78). Es lo que ocurre, por ejemplo, con el cubismo que intenta profundizar en las cosas y poner de relieve la estructura en lugar de la apariencia, y con la física cuántica, para la que el átomo es más real que el fragmento de materia visible (Barzun, 2001, p. 957).

La revolución futurista italiana (1909-1931) -con la publicación de Fondazione e Manifesto del Futurismo, el 20 de febrero de 1909, en el periódico parisino Le Figaro (Humphreys, 2000, p. 7)- marca el "nacimiento, al menos de forma oficial, del primer auténtico movimiento de vanguardia" (Gómez, 2007, p. 199), reclama un arte cruel y violento dispuesto a sembrar los ánimos guerreros en el alma de sus conciudadanos y defiende que todo el patrimonio artístico itálico debe ser quemado para poder construir el futuro (Granés, 2011, pp. 19 y ss.). Mientras tanto en Nueva York (1908-1917) se producen los gérmenes anarquistas de la posterior revolución dadaísta (Granés, 2011, p. 30), que tiene lugar fundamentalmente en Rumanía -con Tristan Tzara, sobre todo (Vlad, 2009, p. 273)- y más tarde en Zurich (1916-1920), caracterizada por la rebeldía y la transgresión, por imitar al salvaje y al niño, negar el arte y reivindicar la vida. Marcel Duchamp (1915-1923), por su parte, anuncia en Nueva York la "rebelión para uno mismo", y el músico John Cage (1937-1952) diluye toda distinción entre arte y vida, al defender que al artista no le compete imaginar, fantasear o reordenar la realidad con el fin de generar un mundo ficticio o una armonía que parezca artificial sino exhibir el mundo tal como es y educar a los demás a aceptarlo. Tras la guerra (1915-1918), en Zurich y en Berlín, el arte prefiere mirar a la niñez y al primitivismo -como había hecho antes el cubismo- y busca la salvación y la fuga del tiempo, algo similar a lo que hará algunos años más tarde (1924-1941) la revolución surrealista, si bien en tanto que para los dadaístas el arte debe curar, según los surrealistas constituye un revulsivo social. Específicamente el surrealismo cree que Occidente, civilización a la que desprecia junto a su fundamento grecolatino, se halla en su "ocaso" y que, por tanto, su futuro está sentenciado. En su lugar, propone reunir máscaras africanas -como había hecho el cubismo- e ídolos y figurillas de Oceanía y de los indios nativos norteamericanos. Así, intenta escapar de la civilización occidental y de su apuesta por la razón y se introduce -como el romanticismo- en el irracionalismo. Todas estas indagaciones artísticas se explican porque tratan de volver a nombrar el mundo destrozado por la conflagración y de salvar a la humanidad, y por eso desean retroceder en el tiempo, hasta la infancia o el estado primitivo, donde desean fundar nuevamente el mundo. Esta fuga del tiempo que permite a los artistas crear su propio paraíso sigue diversos caminos: la idealización de la sociedad futura -Marinetti-, el retorno a la niñez -Ball-, la inclinación hacia lo primitivo e irracional -Huelsenbeck- y el rechazo de todo lo que no fuera diversión o vida -Tzara- (Granés, 2011, pp. 23-86).

En los años 50, en Estados Unidos, entran en juego la juventud insatisfecha, el azar, el caos, la improvisación, la espontaneidad y la colaboración grupal. Por esas mismas fechas (1948-1954), en París, también la rebeldía de los jóvenes deviene el nuevo protagonista de la Historia. Es lo que sucede con la rebelión situacionista que, impulsada por la lucha contra el aburrimiento, se centra en la acción para cambiar la vida en sus más pequeños detalles; se trataba, por tanto, de crear no el arte o la literatura sino el "arte de la vida". Estos son los mismos postulados de otros movimientos de los 60, como el letrismo, el hipismo o el yippismo, propugnados fundamentalmente por los jóvenes, los promotores básicos de la revolución de 
mayo de 1968 que protesta contra el bienestar y el espectáculo, lleno -según su perspectiva- de alienación y de tedio. Además, la revolución de mayo del 68 logró una serie de sucesivas transformaciones de los estilos cotidianos de la vida, destacando al respecto los cambios sociales en las modas, el sexo, el hedonismo, el consumismo, la implosión de los derechos humanos, el empoderamiento de las mujeres, el reconocimiento de las minorías étnicas, raciales, sexuales...

En cuanto a los artistas norteamericanos, existieron dos tipos de revolucionarios, los que se adscriben a la denominada rama psicológica -la de la paz- y los que se incorporan a la sociológica -la de la lucha-. La primera busca el crecimiento personal, la espiritualidad, la armonía y la creatividad, y sus representantes viajan a India, Japón o Nepal para encontrar allí estos valores. Los que detentan la segunda corriente, por su parte, desean el reconocimiento, la identidad y la venganza, lo que esperan hallar en sus viajes primero a Cuba, y más tarde a China (Granés, 2011, pp. 111-217).

En todo caso, las revueltas de estos artistas no consiguen derribar la sociedad y ni la burguesía ni el capitalismo estuvieron nunca en riesgo, por lo que su éxito fue solo parcial. Eso sí, sus propuestas suavizan las jerarquías y los tabúes, legitiman el hedonismo, toleran lo diferente, rozan los márgenes de la libertad individual e inician espacios para la expresión del yo. En este sentido, en 1969 S. Sontag escribe que "atacar el sistema es hacer algo para uno mismo, para mi yo auténtico", lo que quiere decir que la transformación de la sociedad por parte del arte ya no consiste en involucrarse en la política o en los problemas públicos o en crear utopías, sino en impulsar el individualismo más radical. Por tanto -tal y como había anunciado $\mathrm{M}$. Duchamp-, el arte se vinculará a las nociones de genialidad individual, sentimiento, fantasía e invención de reglas inéditas y se transformará en un asunto individual (Eco, 1972, p. 128; Granés, 2011, pp. 197-444).

\section{LA PÉRDIDA DE PROTAGONISMO DE LA JUVEN- TUD Y EL ENVEJECIMIENTO DE LA SOCIEDAD Y DE LA CREATIVIDAD EN LA SEGUNDA MODERNIDAD}

\subsection{El papel de las guerras en el envejecimiento social y cultural}

El característico protagonismo de la energía transformadora de la infancia y de la juventud de la primera modernidad va a dar paso paulatinamente a la decadencia física, cultural y social en la segunda modernidad. $Y$ en ello tienen un peso decisivo tanto los efectos producidos por las guerras que azotaron el siglo XX como el envejecimiento demográfico de la población occidental.

Es probable que en su raíz más profunda la senectud de nuestra civilización, si bien posee causas históricas (Barzun, 2001) que no van a ser tratadas aquí, se encuentre en el hecho de que nuestra actual forma de civilización es impactada por la devastación ocasionada por los dos principales conflictos armados del siglo XX. En la Primera Guerra Mundial, por ejemplo, los individuos que mueren son fundamentalmente los más jóvenes, los más dotados y los más desinteresados. De hecho, en las naciones que participaron en ella (con la excepción de Inglaterra) el servicio militar era obligatorio, de modo que todos los mayores de dieciocho años debían movilizarse; incluso esta edad se adelantó a los dieciséis años al final del conflicto. Así, en los cincuenta y dos meses que duró, fallecieron unos diez millones de personas, a lo que hay que sumar que veinte millones fueron heridas. Sin embargo, la irreparable pérdida que suponen tiene un alcance de más hondo calado que la de la propia muerte de los soldados, ya que los mutilados, los tuberculosos, los enfermos incurables, los traumatizados por la guerra, los entristecidos, los enloquecidos, los suicidas, los espíritus rotos, las carreras destruidas, los genios en ciernes enterrados o los nacimientos no llevados a cabo constituyen todos ellos mermas inconmensurables en el plano humano, social y cultural. En este último sentido, debido a que las autoridades civiles y militares no coordinaron sus planes, ello condujo a que los más lúcidos artistas, científicos, intelectuales y eminentes personalidades de diferentes campos sucumbieran en las trincheras. El mismo riesgo sufrieron las infraestructuras culturales -las obras artísticas, las bibliotecas, los edificios arquitectónicos de interés, catedrales, iglesias, monasterios, palacios, castillos...-. A ello debe añadirse la constante e intensa ansiedad que sufrieron millones de personas por el destino de su país y el de sus familiares y amigos en el frente, lo que causó un obstáculo permanente para una reflexión reposada. Además, en el combate los soldados tenían la sensación de que se acercaba el final, con la consecuencia de que se vieran atraídos por el peligro y la muerte (Barzun, 2001, pp. 1020-1043).

En suma, la guerra representó el insensato derroche de vidas de toda una joven generación que se hubiera enfrentado a las anticuadas visiones y que, por consiguiente, pudiera renovar la sociedad, así como revigorizar los necesarios vínculos con la cultura anterior al conflicto. Pero lo más importante es -como señala el 
historiador J. Barzun (2001, p. 1048)-, que "la devastación, tanto material como moral, había calado tan hondo que sacó la creatividad de su cauce, primero para convertirla en frivolidad -lo que, como he señalado, les ha ocurrido a las artes- y después para llevarla por los caminos de autodestrucción".

\subsection{Una sociedad demográficamente envejecida}

Parece obvio que el actual envejecimiento social y cultural se relacione con la demografía, no en balde la sociedad ha entrado en la fase final de la transición demográfica, un nuevo régimen demográfico lleno de transformaciones que son el resultado de la mejora de la calidad de la vida, de las innovaciones tecnológicas y de los avances de la ciencia médica (las técnicas neonatológicas, los antibióticos, los fármacos, las prótesis, las cirugías...). Así, se han establecido las condiciones para la creación del viejo como una construcción social y del envejecimiento generalizado de la sociedad. Cierto, hoy se manifiesta un fenómeno revolucionario que ha conllevado una gran eficiencia en la reproducción, en tanto que la mayoría de las personas nacidas llegan a ancianas, rompiendo la tradicional tasa del $50 \%$ de fallecidos entre el nacimiento y los quince años. Simultáneamente, ello ha generado un acelerado incremento de la población, no en balde la humanidad ha crecido, como especie, en el último siglo cinco veces más que en el pasado, a la vez que la fecundidad se ha liberado de una reproducción perentoria. $Y$ a ello se le suma que esa fecundidad ha descendido continuamente hasta mínimos insospechados, al mismo tiempo que ha aumentado la esperanza de vida y se ha producido el boom demográfico (Pérez Díaz, 2016, p. 2).

Este cambio de la pirámide, denominado envejecimiento demográfico, ha devenido un asunto multifactorial, polifacético e interdisciplinario que conlleva un peso creciente de las personas longevas. Por ejemplo, junto con el descenso progresivo de la tasa de natalidad (en España, actualmente se encuentra en 1,2) y con la disminución de la mortalidad infantil, se han producido también modificaciones sustanciales en la esperanza de vida al nacer. Así, hoy esta ha aumentado espectacularmente, de modo que la vejez prolongada, conformada por los "viejos jóvenes" (de 60 a 75 años) y los "viejos viejos" (de 75 años en adelante) es ahora experimentada por millones de personas, entre ellas las octogenarias. Por consiguiente, en los países desarrollados los mayores de 64 años superan ya el 15\%, mientras que en España el $17 \%$ de la población cuenta hoy con 65 años o más (Fernández, Parapar, y Ruiz, 2010; Hidalgo González, 2001, pp. 4-65; Pérez y Abellán, 2010).
Así pues, el proceso de envejecimiento de la sociedad contemporánea es evidente y a él se vincula la pérdida de fuerza de convicción y de transformación de la juventud. Sin embargo, el envejecimiento demográfico no constituye la principal causa de ello, sino solo una expresión más de un dilatado proceso de transformación social por el que la juventud ha dejado de tener el lugar central de hace unas pocas décadas (Pérez Díaz, 1998, pp. 2-10).

\subsection{El envejecimiento del arte y la ciencia actuales}

Los calamitosos efectos de las guerras y el progresivo envejecimiento de la población, junto con el agotamiento producido por la intensidad de las energías desplegadas, han confluido en que poco a poco el momento creativo brioso de principios del siglo XX se extinguiera hasta llegar a la decadencia de las artes, las ciencias y la propia sociedad en la segunda modernidad.

En relación al arte, conviene preguntarse cuál es el balance general que puede hacerse sobre el conjunto de las dos vanguardias artísticas, cuáles son sus fracasos y qué aportan finalmente a la sociedad. Ante todo, debe señalarse que ese balance no es totalmente negativo, puesto que la aportación cultural de las vanguardias artísticas ha sido considerable y aún sigue vigente (Granés, 2011, p. 86). Ello se relaciona con el hecho de que ellas fueron asimiladas por la burguesía, la clase social más poderosa del período, contrariamente a lo que sucedió con las novedades científicas, que no fueron comprendidas por ella y que no recibieron ninguna información del arte. De hecho, los científicos más destacados -Einstein, Rutherford, Ehrlich y Baekeland- tienen en común su carácter solitario, autosuficiente y ensimismado (Watson, 2002, pp. 122-123).

Pero al lado de estos aspectos positivos, las primeras vanguardias también poseen otros más negativos. En este sentido, su pretendida búsqueda de originalidad se circunscribe a los inicios, pues poco después se transforma en un mito, en tanto que esa originalidad es en realidad el resultado activo de la repetición y de la recurrencia. El hallazgo de la retícula, por ejemplo, proporciona a los artistas un sentido de comienzo, de nueva salida, de grado cero, de un redescubrimiento, y en suma de hallarse ante su origen. Sin embargo, no les procura la originalidad, sino que les obliga a la repetición, por lo que esta experiencia de lo originario, que ha afectado a generaciones de artistas, críticos y espectadores, es falsa y a la postre constituye una ficción. Consiguientemente, 
el origen de la modernidad artística se disuelve en una replicación sin fin (Krauss, 1996, pp. 171-182), debido al predominio de la reproductibilidad, que se ha transmutado en el postulado esencial de la estética de las vanguardias, y a que la reproducción ha devenido el principio de la creación artística industrial y comercial. Así, se ha puesto fin a los momentos originarios y utópicos que definieron a los pioneros del arte moderno (Subirats, 1989, p. 21).

Por otra parte, con el paso del terrorismo cultural al político, acaba "el primer tiempo de la revolución cultural" en Europa, y desde entonces tanto el arte más transgresor como el terrorismo, si desean tener éxito, necesitan transformar sus acciones y prácticas en un espectáculo. Se explica así que los "rebeldes" del "segundo tiempo de la revolución cultural" lo entronicen y ya no combatan al sistema y que se convierta en uno de los entretenimientos más beneficiosos del capitalismo cultural. Otro ejemplo de ello lo representa la monumentalización de las arquitecturas posmodernas, que intenta alcanzar ciertas metafísicas de lo sublime, y que expresa un culto al poder. $Y$ aunque ciertamente -como ha señalado Arthur $C$. Danto-, el arte actual supone la encarnación misma de la creatividad y de la libertad humanas, al ser profundamente plural y tolerante, al no tener reglas y ser impredecible (Danto, 1999, pp. 20-139), sin embargo cabe plantearse en qué se ha convertido realmente este arte no normativo, incierto e inesperado y qué le diferencia de lo que no lo es. No en balde, la "segunda revolución cultural" es frívola y banal -como ilustra A. Warhol-, constituye un movimiento epigónico y decadente, se "agota" -así lo declara G. Lipovetsky- y se queda sin proyecto ni meta (Granés, 2011, pp. 298-326), es decir, sin narrativa, sin originalidad como origen-originario. $Y$ esto es lo que explica, en último término, que se conduzca hacia su fin, o más bien hacia el final -ya anunciado por Hegel- de una larga etapa histórica y de una importante función social.

En resumen, el drama de las vanguardias consiste en que su huida del pasado, y en cierto sentido también del presente, conduce conscientemente hacia un porvenir sin futuro, sin proyecto y sin sentido, y que "en su vacío cultural, estilístico y artístico, la ruptura, la protesta y la superación vanguardista señale -paradójicamente- (su) obsolescencia, es decir, su muerte" (Subirats, 1989, pp. 21-160).

Finalmente, aunque la ciencia no ha dejado de generar nuevas invenciones y enfoques a lo largo del siglo XX y XXI y de abrir con ellos novedosos conoci- mientos y utilidades, no se ajustan a la perspectiva creativa narrativa y originaria que trato aquí. $Y$ es que lo que el historiador de la ciencia Sánchez Ron (2000, pp. 294-297) denomina la "última revolución científica del siglo" está conformada por disciplinas como la genética, la biología molecular, la biotecnología y la ingeniería genética, que son consideradas ciencias, pero también, en una gran parte, una pura tecnología, pues necesitan para su desarrollo una densa información -ordenadores de alta velocidad y métodos sistemáticos para distribuir, organizar y clasificar esa información-. Es significativo al respecto que en las ciencias biológicas se diga con frecuencia que las sustancias transmiten información -la neurona habla al chip y este a la célula nerviosa- y que existen códigos que regulan tales intercambios (Barzun, 2001, p. 1108).

Por otra parte, ahora se ha acabado la época de las teorías que revisaban las visiones tradicionalmente aceptadas, sin olvidar que, de la ciencia, la tecnología es la única institución que no se ha visto afectada por ninguna disminución de resultados. A ello hay que añadir que en la ciencia ya no rige el sentido común que estuvo presente hasta ahora (Bronowski, 1978, pp. 105-129) y que los informes científicos de asuntos muy diversos suelen ser contradictorios, como ocurre, por ejemplo, con los vinculados con el calentamiento global, el radón en el suelo, el agente naranja, los aditivos alimentarios o la manipulación genética, temas todos ellos de los que es muy difícil hacerse una opinión homogénea inteligente. Se explica así que la sociedad haya perdido la confianza que tenía en la ciencia en el siglo XIX, que esta y la tecnología hayan perdido su santidad y que no se libren de duras críticas sociales y filosóficas que las hacen responsables de los peores males del presente. Entre ellos, que han ayudado a destruir la parte espiritual del ser humano por el exceso de racionalidad y de mecánica; o que han producido miedo a la aniquilación física a que pueden dar lugar las armas nucleares, o desorden psíquico por la manipulación genética o inquietud ante la clonación por sus éticamente dudosos procedimientos (Barzun, 2001, pp. 1109-1177).

Por tanto, la creatividad que representa la ciencia actual no encaja en las coordenadas que aquí estoy delimitando, y además tampoco es comparable, en trascendencia, a la que conforman la física relativa y la cuántica, como se ha visto verdaderamente revolucionarias, rebeldes y juveniles, además de instituyentes de la ciencia posterior. 


\subsection{La decadencia de la democracia}

También la democracia, muy creativa durante la primera modernidad, ha entrado en la segunda en una fase de decadencia. Así, la misma palabra democracia, los rasgos y las cuatro perspectivas que la definen -constitucional, sustantiva, procedimental y procesal (Tilly, 2010, p. 37)- corren hoy el riesgo de vaciar su sentido y de no significar ya nada (Flores d'Arcais, 2013, p. 13). Ello es debido a que las tres o cuatro etapas que ha habido en el desarrollo de la democracia -la liberal de derecho, la liberal-democrática de derecho, la liberalsocial de derecho y el Estado postmaterial-, y que representaban un gran pacto histórico entre las fuerzas del mercado, del trabajo y democráticas, se encuentran en una profunda decadencia o crisis. La razón está, por un lado, en tres agudos problemas: el de la ingobernabilidad, el de la privatización de lo público y el de la existencia de un poder invisible (Bobbio, 2007, pp. 36 y ss.; Bobbio, Pontara y Veca 1985, pp. 12-14; Requejo Coll, 1990, pp. 76-167); y por otro lado, en los riesgos o los enemigos externos -los regímenes totalitarios, los movimientos fundamentalistas-, que se han juntado con los internos -el populismo, el ultraliberalismo y el mesianismo-, hoy dominantes (Todorov, 2012, pp. 8 y ss.).

Se puede observar, entonces, que estas fases de la democracia contemporánea en líneas generales se han conducido, al igual que el propio Estado, desde la estabilidad a la crisis y desde el vigor a la decadencia. $Y$ es que, si hasta los años 60 prevalecía la idea de la "democracia como equilibrio" (Macpherson, 1981), si antes preponderaba la convicción de que esta forma de gobierno era sinónimo de orden estable y de prosperidad generalizada, poco a poco se va perdiendo la fe en sus potencialidades y se la observa como incapaz de solventar con eficacia y eficiencia, con justicia y con igualdad, los numerosos y profundos problemas y desafíos que la aquejan (Roche Cárcel, 2013, p. 58). Ello ha venido acompañado de la polarización de los ideales democráticos, pues ahora se retan entre sí, por un lado, los postulados que defienden que el Estado ha entrado en crisis porque está sobrecargado y, por otro, los que consideran que ha perdido legitimidad, al romperse las relaciones de clase tras la imposición de limitaciones a la política por parte del capital (Held, 1993, pp. 273-277).

\subsection{La senectud de la economía capitalista}

Algo similar sucede con el actual capitalismo que se encuentra en una fase de senectud a la que paradójicamente le fascina lo nuevo, de manera semejante a cómo la vejez se arroba ante la juventud y a cómo el capital envejecido rejuvenece las formas de explotación.
En efecto, la senilidad es el fruto de varias crisis -entre otras, de acumulación, de financiación de las empresas, de pauperización económica y social de las mayorías-. Además, la economía está enferma porque, a diferencia de lo que sucedía tras 1945, cuando se desplegó un ciclo de esperanza, un crecimiento económico extraordinario que se conoce como "edad de oro" (Hobsbawm, 2001, pp. 29 y ss.), ahora tiene por objeto la escasez en lugar de la abundancia, al igual que le sucede a la medicina que se ocupa de la enfermedad en vez de dedicarse a la salud. En paralelo, a medida que el sistema capitalista envejece, invierte cada vez más en tecnología, en instalaciones, en energía, en materias primas, en suelo, etc., es decir, más en trabajo muerto que en trabajo vivo -el trabajo asalariado de las personas-. De ahí que esta desigual proporción represente el auténtico indicador biológico del capitalismo y que manifieste simultáneamente su trágica contradicción. $Y$ es que, aunque el capital requiere del trabajo vivo para que le insufle vida, sorprendentemente lo descarta, al tiempo que se renueva mediante novedosas formas de explotación proporcionadas por la incorporación de nuevas tecnologías. Sin embargo -y así se cierra el perverso bucle-, lo que estas exteriorizan es precisamente la no contratación y la marginación de los trabajadores arrojados a la miseria y a la precariedad por parte de las fuerzas del capital (Amin, 2005, p. 85; Boada, 2017, pp. 63-147).

Por tanto, el viejo capital se convierte hoy en un importante impulsor de la innovación tecnológica, pero no de la social, que había constituido la principal motivación intelectual de la revolución industrial. Como corolario, la economía capitalista se ha desgajado de la sociedad y ha llegado a dominarla (Polanyi, 2017, p. 43 y p. 179), mientras que ha roto el corte social tradicional del capitalismo, puesto que "ya no sería el que opone el capital al trabajo en su conjunto, sino el que enfrenta al bloque acreedor (que asocia el capital y el trabajo) a los excluidos" (Amin, 2005, p. 85). De este modo, se ha roto el gran pacto histórico entre las fuerzas del mercado, del trabajo y democráticas al que he aludido anteriormente y que había definido la conformación de la democracia representativa.

\section{CONCLUSIONES}

5.1. La creatividad se define por la originalidad, que construye una narración histórica y que puede ayudar a eliminar la con-fusión del presente

Como se ha visto en este artículo, tal y como defiende el pensamiento sociológico, la persecución de la originalidad define sustancialmente a la creatividad. Pero, al indagar en la etimología de la palabra origi- 
nalidad, en su vinculación con el proceso creador, se ha desvelado que ella remite tanto al 'origen' como a 'lo originario' u 'originante'. También que ambos términos van juntos, que están fusionados en una intrincada interrelación, en tanto que el origen constituye el fundamento de lo originario, y en la medida en que la pretendida originalidad de la creación literaria, artística, científica o de cualquier otro campo social o cultural constituye un proceso dialéctico que conduce a una vuelta a los orígenes que al tiempo anuncia el porvenir. Así, la creatividad construye una narración histórica, relacionada con la génesis y el destino, con el principio y el final, y en suma con el pasado que instituye y el futuro institucionalizador.

Esta narración vincula, pues, las tres temporalidades: el pasado, el presente y el futuro. El retorno a lo precedente constituye una necesidad psicológica y social, en cuanto que en él se halla una energía vital originaria, una especial intensidad emocional y una simplificación que compensan la insatisfacción, las carencias y la complejidad del presente. Este, por su parte, que se halla en crisis o que se siente como insuficiente o demasiado complejo y que es el que reclama una creatividad superadora, queda insuflado de una transitoria energía vital originaria, de una intensidad emocional revigorizada temporalmente -o, mejor, en términos sociológicos, de una "efervescencia" (Durkheim, 2017, p. 156) o de una "energía emocional" (Collins, 2009, pp. 141 y ss.)- procedente de la fuente originaria. Insuflado de energía, el presente puede construir el futuro e instaurar en él una renovada complejidad individual y social, aún no agotada por el paso del tiempo. Sin embargo, lo paradójico es que esta generación del porvenir no deja de sustentarse sobre una vuelta al pasado que simultáneamente expresa una huida. Cierto, si la creatividad revisa el tiempo pretérito también intenta superarlo, con la finalidad última de desarrollar algo novedoso.

Por consiguiente, el porvenir queda fundado -enraizado y legitimado- en el pasado, mientras que el presente actúa de intermediario entre las otras dos temporalidades. Sin olvidar que este estado contemporáneo, mediante el proceso de creación que termina fundiéndose con lo remoto que lo sustenta y con el porvenir que genera, se llena de sentido, se experimenta intensamente, y a la postre es clarificado epistemológicamente.

En definitiva, la narrativa histórica que construye la creatividad es posible que ayude a abolir la confusión en la que está instalado el presente (Sánchez Capdequí, 2010).

\subsection{La infantilidad y la juventud de los creadores y el conflicto generacional}

El origen de la creatividad, que es consustancial a la propia vida, al vivir creador, a la condición de estar vivo, y que acompaña a los seres humanos desde su nacimiento hasta su muerte, se asienta en la época de la infancia; es más, la infantilidad constituye uno de los rasgos definidores de los creadores. Concretamente -según el Psicoanálisis- las obras de creación brotan del reino de las madres y suponen un proceso de reparación del trauma infantil experimentado por el abandono de la progenitora, y por eso el sufrimiento pretérito del creador se halla en la base de su creación.

Sin embargo, desde mi perspectiva, la creatividad no puede entenderse únicamente -como indica Freud y un importante sector del Psicoanálisis- como una resta, como una respuesta ante el sufrimiento o la infelicidad, sino también como un deseo muy humano de ser feliz, de trascender la propia naturaleza, de hacer más vida -en la visión simmeliana-, de posibilitar que esta tenga un mayor alcance significativo y una mayor intensidad.

Junto a la infancia, es la juventud la más creadora, la que posee un aspecto más tempestuoso e innovador, los sentimientos novedosos y frescos y las ideas para una nueva vida, y por eso los jóvenes representan la fotografía de los tiempos que cambian. Pero todo ello lo logran mediante el choque entre la cosmovisión juvenil y la de la propia sociedad -particularmente, la de los mayores-. De ahí el rol fundamental que ejercita el conflicto entre generaciones -del que se han ocupado Mannheim, Ortega o Bauman, especialmente-. Aquí me he detenido en lo que significa el concepto de generaciones, qué papel asumen los jóvenes en ellas, cómo funciona y cómo se vinculan con la creatividad. Lo importante de todo ello es que la generación se radica en el ritmo biológico del nacimiento y de la muerte, que comporta un choque generacional del creador consigo mismo y con su sociedad y que constituye un concepto fundamental del acontecer histórico social. $Y$ es que las generaciones se solapan o empalman $y$, por tanto, entran en conflicto, constituyendo la materia de la convivencia social y de su dinamismo dramático. No en balde existen dos tipos de generaciones: las de los jóvenes que combaten a los viejos -es lo que ocurre, sobre todo, al principio de la primera modernidad-y las de los jóvenes que conviven con los mayores, con los que aquellos se solidarizan y a los que se supeditan -es lo que sucede con la envejecida segunda modernidad en la que la juventud ha perdido el protagonismo anterior-. 
La dialéctica producida por este conflicto de generaciones suele desplegarse de la siguiente manera. La generación forjadora de la cultura normativa -ha quedado aquí ejemplificada en los artistas de las primeras vanguardias y en los grandes físicos relativos y cuánticos- envejece, muere, y se retira al cumplir los 60 años, produciendo el olvido de esa cultura por parte de las nuevas generaciones, algo, por otra parte, necesario para el habitual acontecer social producido por el combate entre jóvenes y viejos. Sin embargo, la creatividad recuerda constantemente que la memoria social es tan imprescindible para la sociedad como su extravío histórico (Mannheim, 1993, p. 213) y de ahí que la dialéctica existente en ella entre el origen y lo originario, motivo fundamental de este trabajo, sea apropiada para expresar la lucha generacional entre los adultos que reciben, viven, archivan, ritualizan y protegen la memoria colectiva de sus antepasados, el fundamento del lazo social (Halbwachs, 2011, pp. 25 y ss. y pp. 99 y ss.), "la contrapartida apropiada de la historia" (Ricoeur, 2010, p. 158), y los jóvenes que desean borrarla para crear una nueva, la suya propia.

\subsection{La primera modernidad constituye una etapa in- fantil o juvenil}

Este conflicto entre generaciones se ha evidenciado en la primera modernidad, particularmente entre los años 1905-1908, una etapa muy creativa que ha generado cuatro formas innovadoras de energía: la praxis y la devoción por la violencia, los grandes éxitos artísticos, las innovaciones científicas y las reformas sociales -las concepciones del Estado y de la democracia, más específicamente-. En líneas generales, puede decirse que estas cuatro invenciones han pasado desde una etapa de rejuvenecimiento a otra de decadencia o envejecimiento.

En efecto, puede considerarse en conjunto la primera modernidad como una fase infantil o adolescente, y por tanto inmadura, en la que sobresale su carácter "asesino" -las terribles guerras y convulsiones socioculturales modernas- junto a su aspecto innovador -especialmente en la ciencia y el arte-. De ahí que la creatividad infantil y juvenil de la primera modernidad haya sido tan potente que haya logrado revitalizar la sociedad, pero también que se haya acompañado de una enorme destrucción.

En la visión de Einstein, el espacio y el tiempo se convierten en relativos y en "arenas movedizas", constituyendo el precedente del posterior "mundo sin tiempo" anunciado por la ciencia en el que ya no hay presente (Rovelli, 2018, pp. 33-72 y ss.) y en el que todo se desvanece (de ahí a la con-fusión contemporánea no hay más que un peldaño). Por otra parte, el descubrimiento del big bang -resultado de los avances conjuntos de la física relativa y de la cuánticasimboliza el anhelo de vuelta al origen característico del período moderno y, en paralelo, una legitimación por vía científica del mismo. No en balde, y esto es muy significativo, la expansión del universo que inicia y que, al parecer, acabará con una deflagración con tintes apocalípticos (un big crunch) denota la huella mítica en esta narrativa científica del universo de los libros bíblicos del Génesis y del Apocalipsis. Pero si se piensa bien, esto expresa otra manera indirecta de nostalgia del paraíso, de añoranza de la originalidad. Al mismo tiempo, esta supone una nueva recreación reflexiva del origen, con un elaborado y abstracto contenido matemático y geométrico, con el ánimo de pensar, imaginar y construir el futuro.

También se ha evidenciado el carácter bárbaro o infantil del artista moderno, que es un hombre-niño o un genio que representa la infancia recobrada. Igualmente, la praxis artística moderna se asocia con la juventud rebelde o revolucionaria, que -en esencia- trata de renombrar a un mundo destrozado por la conflagración, y para ello retrocede en el tiempo hasta la infancia o el estado primitivo de la humanidad, con el que intenta fundar nuevamente la sociedad.

Ahora bien, lo que tienen en común las creaciones de la primera modernidad de la ciencia física y de las artes -el cubismo, de un modo destacado- es la persecución de una realidad más profunda, algo que, por cierto, también constituye el origen del proceso creador.

\subsection{El declive generalizado físico, cultural y social de la segunda modernidad}

La energía regeneradora de la infancia y de la juventud característica de la primera modernidad artística y científica dio paso a un declive generalizado físico, cultural y social en la segunda modernidad. Un peso decisivo en esta transformación lo tienen las guerras que asolaron el siglo XX y el envejecimiento demográfico de la población occidental.

En efecto, a la primera modernidad le sigue otra presta a ser madurada por los requisitos de la propia sociedad y por sus deseos de hedonismo y de pacificación, harta de tanta barbarie y sufrimiento. Así, la segunda modernidad será menos dada a las grandes convulsiones -aunque en ella sigan existiendo conflictos regionales, muchos de ellos heredados de la primera- y parece más dominada por los adultos, por ser 
una sociedad -y una civilización- que va camino de la decadencia o del envejecimiento. Como se ha visto, es lo que ha ocurrido con el arte mecanizado y repetitivo y con la tecnificación de la ciencia. Como si se hubiera agotado la energía desplegada por los creadores infantilizados y con rebeldía juvenil, como si los creadores y su ideal se hubieran plegado o se hubieran visto obligados a ello, a los designios del sistema instaurado por sus antecesores mayores.

Estoy convencido de que, en la raíz de este fenómeno social se sitúa el impacto de las dos guerras mundiales, con la aparejada masacre de millones de jóvenes, entre ellos los más preparados y los más creativos. Y es que, debido al impacto de esos conflictos armados, la creatividad se sale de su cauce (de su narrativa temporal diría yo, en coherencia con lo expresado en este artículo), como si la Historia hubiera sucumbido, como si la cultura quedara atraída -al igual que los jóvenes soldados- por una pasión por el final que reemplaza a la del origen (Roche Cárcel, 2007 , pp. 37 y ss.) o como si se convirtiera en frívola y en autodestructiva. La creatividad ha dejado, pues, de ser constructiva para entenderse mayoritariamente como deconstructora o destructora.

También el envejecimiento demográfico contribuye a esta general decadencia social, en la medida en que conlleva toda una serie de consecuencias de primer nivel humanas, sociales, culturales, económicas y, desde luego, en el campo de la creatividad. En este último sentido, ocasiona una pérdida considerable de vitalidad colectiva por la ausencia de la juventud promotora de la creatividad y del impulso emprendedor, así como la correlativa amenaza de parálisis, decadencia o extinción (Pérez Díaz, 1998, pp. 2-10). Por otro lado, amortigua el deseo de rebelión de los jóvenes, al existir una convivencia generacional con los mayores que posibilita una mayor vinculación por las líneas de filiación, y el desarrollo de más lazos verticales de relación, de apoyo, de consejo, de intercambios, de afectos, etc. En consecuencia, los jóvenes no desean tanto liberarse u oponerse a los postulados de los viejos de la sociedad.

Las guerras y el envejecimiento generalizado de la sociedad corren paralelos a la senectud de las artes, de la ciencia, de la democracia y del capitalismo. En cuanto a las artes, el origen que perseguían las vanguardias termina disolviéndose en una replicación sin fin, sin sentido, sin objetivos ni metas y, por tanto, sin pasado ni futuro. Como consecuencia, la creatividad máxima que parece acompañar al arte tardomoderno liberado de estilos y de normas, sin embargo, no pa- rece enfocada a dilucidar cuál es su fundamento o su proyecto, y en suma en qué se ha transformado, hacia dónde se dirige y qué aporta a la sociedad contemporánea. La ciencia, por su parte, se ha transmutado en gran parte en tecnología, ha dejado de producir grandes teorías sustitutorias de la vieja física, ha extraviado una parte considerable de su legitimidad llenando de miedos a la sociedad, y se ha hecho más opaca, más elitista y menos transparente, profundizando de este modo en las diferencias sociales.

La democracia representativa tampoco se halla en su mejor momento. Sus enemigos interiores y exteriores se han acrecentado en cantidad y en calidad y ha perdido gran parte de su legitimidad -como la ciencia-, al tiempo que, en vez de encontrar el equilibrio que logró en la mayor parte de la primera modernidad, ha visto incrementada la polarización ideológica y social.

Finalmente, el capitalismo senil -según lo definen diversos autores- también se ha vuelto profundamente separador, en la medida en que ha devenido un originante de la exclusión, de la marginación y de la desigualdad y no el conformador de una nueva utopía social transformadora e integradora. En esto se asemeja a la democracia representativa, que ya no logra unir a la sociedad, sino más bien expresar que esta se rompe en mil pedazos. Pero lo característico del capitalismo es que, al expulsar a una parte importante de la población, especialmente a los jóvenes, debilita al sistema, al tiempo que lo envejece todavía más, lo que explica que se haya instalado -en opinión de S. Amin- "un caos permanente que conducirá, o bien -en el mejor de los casos- a que se lo supere mediante el comienzo de una larga transición hacia el socialismo, o bien en la peor de las hipótesis- a la catástrofe y al suicidio de la humanidad" (Amin, 2005, p. 10 y p. 155).

Por eso, lo que ha disminuido la senilidad del sistema capitalista es la potencia de la creatividad instituyente, lo que sorprende por cuanto que esta se estimulaba siempre precisamente en momentos de crisis; por el contrario, la creatividad actual parece achicarse como nunca antes había sucedido al tiempo que se agiganta la crisis. Pero hay algo más, lo más fatídico es que lo que realmente está hoy en juego con el desgaste de la creatividad, con la atrofia de su narratividad, con la disminución de su efervescencia, de su intensidad energética y emocional es la continuidad de la construcción de la civilización humana -como el economista aludido explicita- e incluso su propia supervivencia. 


\section{NOTAS}

1. A las tres formas de energía que señala Barzun (2001, p. 1005) le he añadido la ciencia. De estas cuatro energías, la ciencia y las artes son consideradas por los expertos como juveniles por su espíritu innovador y rebelde. Además, los grandes creadores del período eran todos jóvenes. Por ejemplo, Picasso tenía 26 años cuando pintó Las señoritas de Aviñón, que originó el cubismo; Einstein contaba con 26 años cuando ideó la teoría de la rela-

\section{BIBLIOGRAFÍA}

Amin, S. (2005). Más allá del capitalismo senil. Por un siglo XXI no norteamericano. Buenos Aires, Barcelona, México: Paidós.

Barzun, J. (2001). Del amanecer a la decadencia. Quinientos años de vida cultural en Occidente (de 1500 a nuestros días). Madrid: Taurus.

Baudelaire, Ch. (2004). El pintor de la vida moderna. Murcia: Colegio Oficial de Aparejadores y Arquitectos Técnicos, Consejería de Educación y Cultura, Fundación Caja Murcia.

Bauman, Z. y Leoncini, Th. (2018). Generación líquida. Transformaciones en la era 3.0. Barcelona: Paidós. https://doi. org/10.32870/dgedj.v0i9.171

Bell, D. (1992). Las contradicciones culturales del capitalismo. Madrid: Alianza.

Boada, LI. (2017). La senectud del capitalismo. Un reto a la juventud. Barcelona: EDLibros.

Bobbio, N., Pontara, F. y Veca, S. (1985). Crisis de la democracia. Barcelona: Ariel.

Bobbio, N. (2007). El futuro de la democracia México: Fondo de Cultura Económica.

Bronowski, J. (1978). El sentido común de la ciencia. Barcelona: Península.

Chown, M. (2007). El zoo cuántico. Guía turística del interminable universo. Barcelona: La liebre de marzo.

Collins, R. (2009). Cadenas de rituales de interacción. Barcelona: Anthropos.

Danto, A. C. (1999). Después del fin del arte. El arte contemporáneo y el linde de la historia. Barcelona: Paidós.

Durkheim, E. (1987). Historia de la educación y de las doctrinas pedagógicas. Madrid: La Piqueta. tividad; Marinetti tenía 32 años cuando hizo el manifiesto futurista y Tristan Tzara 22 años cuando proclamó el suyo; Heisenberg contaba con 26 años cuando inventó el principio de incertidumbre. La lista podría extenderse, pero creo que estos casos son suficientemente significativos y representativos. En cuanto a las otras dos energías modernas, la democracia y el capitalismo, ciertamente fueron creativas e innovadoras -a ellas les dedicaré

Durkheim, E. (2017). La efervescencia religiosa. En Sánchez Capdequí, C. (ed.). La creatividad social: narrativas de un concepto actual. Madrid: Centro de Investigaciones Sociológicas, pp. 151-169.

Eco, U. (1972). La definición del arte. BarceIona: Martínez Roca.

Elias, N. (2000). Teoría del símbolo. Un ensayo de antropología cultural. Barcelona: Península.

Elias, N. (2013). Sobre el tiempo. México: Fondo de Cultura Económico.

Fernández, J. L, Parapar, C. y Ruiz, M. (2010). El envejecimiento de la población. Lychnos. Cuadernos de la Fundación General CSIC, 2. [En línea]. Disponible en http:// www.fgcsic.es/lychnos/es_es/articulos/ envejecimiento_poblacion

Flores d'Arcais, P. (2013). ¡Democracia! Libertad privada y libertad rebelde. Barcelona: Galaxia Gutenberg, Círculo de Lectores.

Gardner, H. (2010). Mentes creativas: una anatomía de la creatividad. Barcelona: Paidós.

Gómez, L. (2007). L'arte di far manifesti y las publicaciones futuristas 1909-1920. CIC. Cuadernos de Información y Comunicación, 12, pp. 199-208.

Granés, C. (2011). El puño invisible. Arte, revolución y un siglo de cambios culturales. Madrid: Taurus.

Green, A. (1993). La madre muerta. En Green, A. Narcisismo de vida, narcisismo de muerte. Buenos Aires: Amorrortu.

Greene, B. (2006). El universo elegante. Supercuerdas, dimensiones ocultas y la búsqueda de una teoría final. Barcelona: Booket.

Halbwachs, M. (2011). La memoria colectiva. Buenos Aires: Miño y Dávila. un próximo artículo sobre esta cuestión-, pero no pueden ser catalogadas como rebeldes y en choque con las generaciones anteriores -caracteres esenciales de lo creador juvenil-; además, no conozco ningún autor que las haya calificado como creaciones juveniles. Por eso, no me han servido como ejemplos de creaciones juveniles y sí, por el contrario, de creaciones envejecidas -importantes investigadores han utilizado este término-

Held, D. (1993). Modelos de democracia. Madrid: Alianza.

Hidalgo González, J. G. (2001). El envejecimiento. Aspectos sociales. San José: Editorial de la Universidad de Costa Rica.

Hobsbawm, E. (2001). Historia del Siglo XX. Barcelona: Crítica.

Hobsbawm, E. (2013). Un tiempo de rupturas. Sociedad y cultura en el siglo XX. Barcelona: Crítica.

Humphreys, R. (2000). Futurismo. Londres: Ediciones Encuentro.

Joas, H. (2013). La creatividad de la acción. Madrid: Centro de Investigaciones Sociológicas.

Jung, C. G. (2014). Sobre el fenómeno del espíritu en el arte y en la ciencia. Madrid: Trotta.

Jung, C. G. (2015). Arquetipos e inconsciente colectivo. Barcelona: Paidós.

Krauss, R. (1996). La originalidad de la vanguardia y otros mitos modernos. Madrid: Alianza.

López Mondéjar, L. (2015). Una espina en la carne. Psicoanálisis y creatividad. Madrid: Psimática.

Macpherson, C. B. (1981). La democracia liberal y su época. Madrid: Alianza.

Mannheim, K. (1993). El problema de las generaciones. Reis, 62, pp. 193-242. https://doi.org/10.2307/40183643

Martin, M. (2008). La teoría de las generaciones de Ortega y Gasset: una lectura del siglo XXI. Tiempo y espacio, 20, pp. 98-110.

Moliner, M. (2007). Diccionario de uso del español. Madrid: Gredos.

Neumann, E. (2004). El hombre creador y la transformación. En Neumann, E, Elia- 
de, M., Durand, G., Kawai, H. y Zuckerhand, V. Los dioses ocultos: Círculo de Eranos II. Cuadernos de Eranos - Eranos Jahrbücher. Barcelona: Anthropos, pp. 19-66.

Ortega y Gasset, J. (1983). El tema de nuestro tiempo. Madrid: Revista de Occidente / Alianza.

Ortega y Gasset, J. (2008). En torno a Galileo. Madrid: Revista de Occidente / Alianza.

Pérez Díaz, J. (1998), La demografía y el envejecimiento de las poblaciones. En Staab, A. S. y Hodges, L. C. Enfermería gerontológica. México D.F.: McGraw Hill, pp. 451-463.

Pérez Díaz, J. (2016). El temor al envejecimiento demográfico. En Subirats $\mathrm{Hu}$ met, J., Ezquerra, S., Pérez Salanova, M. y Pla, M. (eds.) Edades en transición. Envejecer en el siglo XXI. Edades, condiciones de vida, participación e incorporación tecnológica en el cambio de época. Barcelona: Ariel, pp. 44-54.

Pérez, J. y Abellán, A. (2010). Sociedades longevas: un desafío para el Siglo XXI. Lychnos. Cuadernos de la Fundación General CSIC, 2. [En línea]. Disponible en http://www.fgcsic.es/lychnos/es_es/ articulos/sociedades_longevas_desafio

Polanyi, K. (2017). La gran transformación. Los orígenes políticos y económicos de nuestro tiempo. México: Fondo de Cultura Económico.

Requejo Coll, F. (1990). Las democracias. Democracia antigua, democracia liberal y estado de bienestar. Ariel: Barcelona.

Ricoeur, P. (2010). La memoria, la historia, el olvido. Madrid: Trotta.

Roche Cárcel, J. A. (2007). De la nostalgia por el origen a la pasión por el final. De la génesis de la sociedad al fin de lo social. En Roche Cárcel, J. A. (coord.). Espacios y tiempos inciertos de la cultura. Barcelona: Anthropos, pp. 37-68.

Roche Cárcel, J. A. (2013). La frágil construcción de la democracia en la Grecia Antigua. Res Publica. Revista de Filosofía Política, 30, pp. 15-58.

Rovelli, C. (2018). El orden del tiempo. Barcelona: Anagrama.

Rubio Arostegui, J. A., Pecourt, J. y Rius Ulldemolins, J. (2016). Usos y abusos de la creatividad. Sociología de los procesos creativos, transiciones a lo digital y políticas creativas. Debats, 130 (2), pp. 125145. https://doi.org/10.28939/iam. debats.130-2.7

Sánchez Capdequí, C. (2018). Las sociologías post 68 y la creatividad social. Arbor, 194 (787), a435. https://doi. org/10.3989/arbor.2018.787n1008
Sánchez Capdequí, C. (2010). En los límites de la con-fusión. Miedos, riesgos y urgencias de la sociedad de la información. Madrid: Los libros de la Catarata.

Sánchez Ron, J. M. (2000). El siglo de la ciencia. Madrid: Taurus.

Seco, M. (1999). Diccionario de dudas y dificultades de la lengua española. Madrid: Espasa Calpe.

Steiner, G. (2002). Gramáticas de la creación. Madrid: Siruela.

Subirats, E. (1989). El final de las vanguardias. Barcelona: Anthropos.

Tilly, Ch. (2010): Democracia. Madrid: Akal.

Todorov, T. (2012). Los enemigos íntimos de la democracia. Barcelona: Galaxia Gutenberg-Círculo de Lectores.

Vlad, C. A. (2009). Dadá: Bucarest, Zurich, París. Una historia del dadaísmo. Quintana. Revista de Estudos do Departamento de Historia da Arte, 8, pp. 271-279.

Watson, P. (2002). Historia intelectual del siglo XX. Barcelona: Crítica.

Wilson, E. O. (2018). Los orígenes de la creatividad humana. Barcelona: Crítica.

Winnicott, D. W. (2013). Realidad y juego. Barcelona: Gedisa. 